\title{
Job Satisfaction and Absenteeism interface in Corporate Sector - A study
}

\author{
Prof. V.P. Thirulogasundaram, Dr.P.C.Sahu \\ Principal, Aditya Institute of Management Studies and Research. Bangalore. \\ AMC, Bangalore
}

\begin{abstract}
There are so many reasons for which employees are remaining absent on their duties. Most of the previous researchers had concluded that absence on duty is a complex variable and that it is influenced by multiple causes, of personal as well as organizational. But in our study we paid much importance to job satisfaction and motivation of employees, to make motivate to an employee, job satisfaction is essential. Job satisfaction is linked with motivation and it has been considered as one of the instrumental factor that influencing an employee to attend and perform systematically the assigned jobs. There are generally two factors i.e. intrinsic and extrinsic influencing job satisfactions. Extrinsic factors are influencing more. As extrinsic sources of job satisfaction includes Pay, work, promotion, supervision, co-workers, working conditions, leave, and fairness only. In this study we have obtained the results how that the extrinsic sources of job satisfaction have a direct impact on absenteeism. Thus, in this paper we have paid much importance that employers should pay required attention to extrinsic sources of job satisfaction to motivate and that will help to reduce absenteeism.
\end{abstract}

Key words: Absenteeism, Motivation, Job satisfaction, intrinsic, and extrinsic

\section{Introduction}

Absenteeism has long been considered a significant and pervasive problem in industry. Low job motivation represents the primary cause of absenteeism As a result, theories have been developed and numerous studies conducted to identify the causes of absenteeism. Probably one of the most common theories is the notion that absenteeism is caused by employees avoiding a painful or dissatisfying work situation. By the same token, this hedonistic theory would predict that employees who find their job more challenging, more interesting, or more pleasurable in other ways will be absent less often than employees who find their work less pleasurable. Although it is recognized that absenteeism may be caused by the employee's inability to come to work, motivation to attend work is assumed to be a major factor determining how often an employee is absent. To many in the world of work, absenteeism is one of those stubborn problems for which there is no clear culprit and no easy cures (Rhodes \& Steers, 1990, p. 1). One of these factors which have been cited by different researchers is an employee's level of low job motivation in the workplace is dissatisfaction with their job. In conjunction with this, George and Jones (2002, p. 93) maintain that "...many researchers have studied the relationship between absenteeism and job satisfaction in an attempt to discover ways to reduce absenteeism."

\section{Meaning and definition}

In simple, frequent or habitual absence from work or voluntary non attendance at work is known as absenteeism. Without valid reason Absenteeism means either habitual evasion of work, or willful absence as in a strike action. It does not include involuntary or occasional absence due to valid causes, or reasons beyond one's control, such as accidents or sickness.

Absenteeism is a habitual pattern of absence from a duty or obligation. Traditionally, absenteeism has been viewed as an indicator of poor individual's performance, as well as a bread of an implicitly contract between employee and employer, it was seen as a management problem, and framed in economic or quasieconomic terms. More recent scholarship seeks to understand absenteeism as a indicator of psychological, medical, or social adjustment to work, Johns, Gary (2007) "absenteeism" in George Ritzer (ed.). High absenteeism in the workplace may be indicative of poor morale, but absences can also be caused by workplace hazards or sick building syndrome. Many employers use statistics such as the Bradford factor that do not distinguish between genuine illness and absence for inappropriate reasons.

As a result, many employees feel obliged to come to work while ill, and transmit communicable diseases to their co-workers. This leads to even greater absenteeism and reduced productivity among other workers who try to work while ill. Work forces often excuse absenteeism caused by medical reasons if the worker supplies a doctor's note or other form of documentation. Sometimes, people choose not to show up for work and do not call 
in advance, which businesses may find to be unprofessional and inconsiderate. This is called a "no call, no show". According to Nelson \& Quick (2008) people who are dissatisfied with their jobs are absent more frequently. They went on to say that the type of dissatisfaction that most often leads employees to miss work is dissatisfaction with the work itself.

The psychological model that discusses this is the "withdrawal model", which assumes that absenteeism represents individual withdrawal from dissatisfying working conditions. This finds empirical support in a negative association between absence and job satisfaction, especially satisfaction with the work itself, Johns, Gary (2007). Medical-based understanding of absenteeism find support in research that links absenteeism with smoking, problem drinking, low back pain, and migraines Johns, Gary (2007). Absence ascribed to medical causes is often still, at least in part, voluntary. Research shows that over one trillion dollars is lost annually due to productivity shortages as a result of medical-related absenteeism, and that increased focus on preventative wellness could reduce these costs, Mc Clenney, Mary Ann, 1992. The line between psychological and medical causation is blurry, given that there are positive links between both work stress and depression and absenteeism, Johns, Gary (2007). Depressive tendencies may lie behind some of the absence ascribed to poor physical health, as with adoption of a "culturally approved sick role". This places the adjective "sickness" before the word "absence", and carries a burden of more proof than is usually offered.

Evidence indicates that absence is generally viewed as "mildly deviant workplace behavior". For example, people tend to hold negative stereotypes of absentees, under report their own absenteeism, and believe their own attendance record is better than that of their peers. Negative attributions about absence then bring about three outcomes: the behavior is open to social control, sensitive to social context, and is a potential source of workplace conflict. Thomas suggests that there tends to be a higher level of stress with people who work with or interact with a narcissist, which in turn increase absenteeism and staff turnover, Mc Clenney, Mary Ann, "A Study of the Relationship Between Absenteeism and Job Satisfaction, Certain Personal Characteristics, and Situational Factors for Employees in a Public Agency" (1992), Applied Research Projects Paper 241.

\section{Objective of the study}

- The main objective of this study is to find out the reality of absenteeism of employees on their duty.

- Impact of motivation and job satisfaction on absenteeism.

Variables of employee remains absent in work

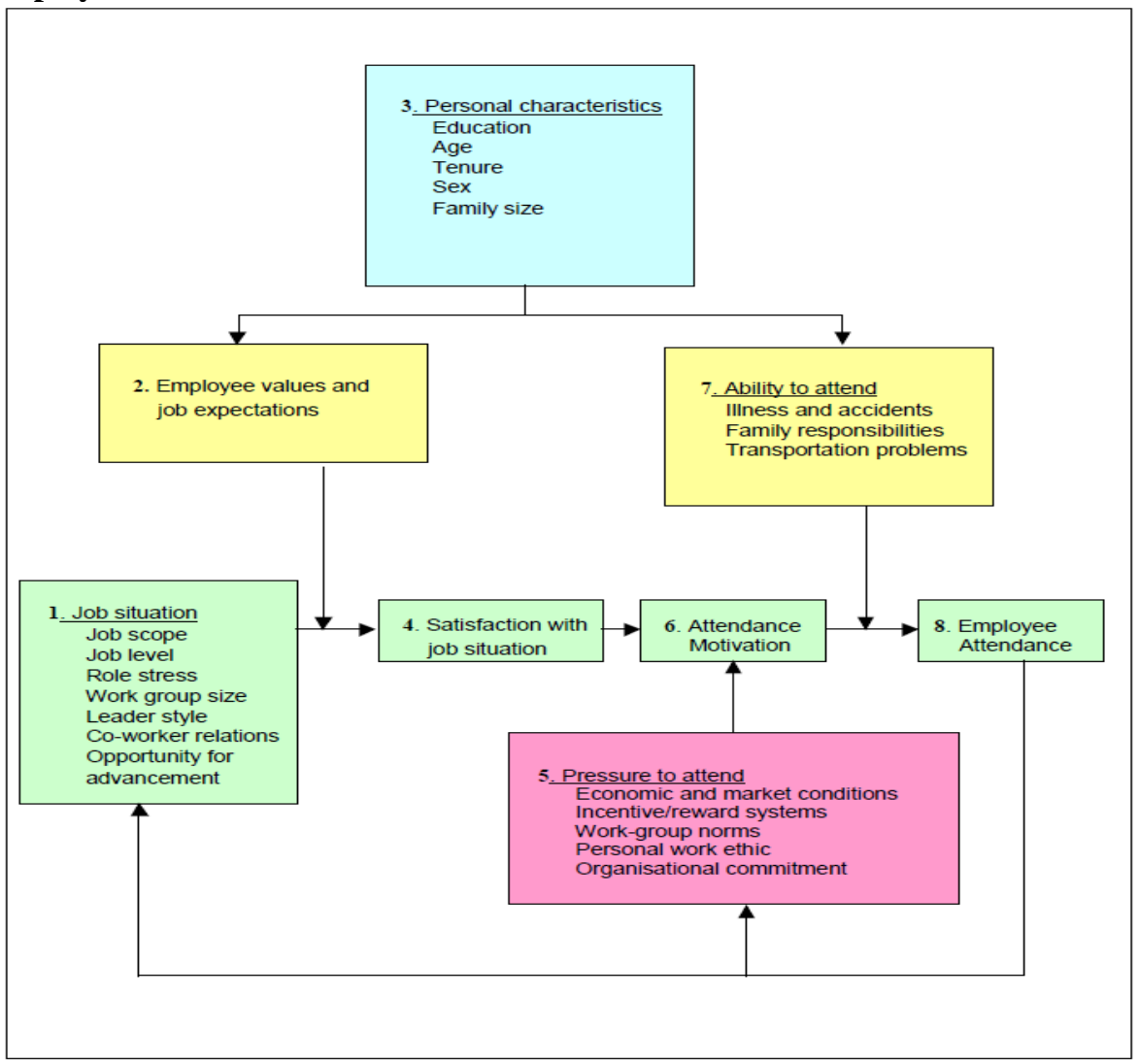

Variables of employees absent (Source: Rhodes \& Steers (1990, p. 46) 


\section{Literature review}

According to Luthans (1995), research has generally revealed a consistent inverse relationship between job satisfaction and absenteeism, i.e. when satisfaction is high, absenteeism tends to be low and when satisfaction is low, absenteeism tends to be high. Even though this correlation has been found to be rather moderate, the underlying assumption is that absence is at least in part, the result of dissatisfaction on the job (Anderson, 2004; Hardy, Woods \& Wall, 2003). There is a further suggestion that the effects of job satisfaction will be more evident from the frequency of absences rather than from the total number of days absent (Johns, 1996).

However, even though it makes sense that dissatisfied employees are more likely to miss work, absenteeism is a complex variable and is influenced by multiple factors. (Robbins,1998; Robbins, Odendaal \& Roodt, 2003; Spector, 1997). Steers et al. (1996) supported the notion that employees who are dissatisfied with various aspects of their jobs are more likely to be absent.

\section{Methodology}

By adopting random sampling method the data have been collected through questionnaire method from 200 respondents from Bharat Heavy Electricals Limited, Trichi, Tamilnadu. The help of secondary data of the organizations has also been taken for the study. The various statistical tools are used to find out the significance level i.e. relation with job satisfaction, motivation and absenteeism.

\section{The analysis and interpretation of data}

Seven major extrinsic factors of job motivation relative to absenteeism are considered and based on the data obtained from the field survey; each of the sources of job motivation plays a significant impact on absenteeism. This is presented in Table 1 .

Table 1: Summarized Result of the Seven Factors of Motivation/Job Satisfaction

\begin{tabular}{|c|c|c|c|c|c|c|c|}
\hline $\begin{array}{c}\text { Motivational } \\
\text { factors relative } \\
\text { to absenteeism }\end{array}$ & $\begin{array}{c}\text { Pay } \\
\mathbf{( \% )}\end{array}$ & $\begin{array}{c}\text { Promotion } \\
(\boldsymbol{\%}\end{array}$ & $\begin{array}{c}\text { Work } \\
\text { Interest } \\
(\boldsymbol{\%})\end{array}$ & $\begin{array}{c}\text { Supervision } \\
(\boldsymbol{\%}\end{array}$ & $\begin{array}{c}\text { Co- } \\
\text { workers } \\
(\boldsymbol{\%})\end{array}$ & $\begin{array}{c}\text { Working } \\
\text { condition } \\
(\boldsymbol{\%}\end{array}$ & $\begin{array}{c}\text { Fairness } \\
(\boldsymbol{\%})\end{array}$ \\
\hline Strongly disagree & 2 & 4 & 0 & 6 & 10 & 2 & 3 \\
\hline Disagree & 6 & 1 & 2 & 4 & 14 & 6 & 1 \\
\hline Undecided & 10 & 2 & 1 & 1 & 20 & 2 & 1 \\
\hline Agre & 24 & 2 & 1 & 2 & 20 & 5 & 2 \\
\hline Strongly agree & 58 & 4 & 7 & 5 & 36 & 4 & 5 \\
\hline Mean & 4. & 3 & 4. & 4. & 3. & 4 & 4. \\
\hline
\end{tabular}

Source: Compilation of Primary data

The above table depicts that $82 \%$ (mean 4.3) of the entire respondents opined that pay has a significant impact on motivation/absenteeism. It thus means that if the pay does not commensurate with the work done by workers, there exist a very high tendency for the worker to stay absent from work or rather look for a greener pasture. They are of the opinion that, it is the fairness of pay that determines satisfaction rather than the actual level of pay itself. If an employee's compensation is therefore perceived to be equitable when compared to another similar position, satisfaction might be the likely result. That $62 \%$ (mean 3.8) of the respondents opined that promotion is a benefitting factor that can motivate workers to serve the company beyond expectations as they become accrued with more responsibilities. They claim that promotion provides employees with opportunities for personal growth, more responsibilities and also increased social status. Not only does it yield job satisfaction, reduce job absenteeism rate, improve workers standard but also improve the company's corporate image.

Employees tend to prefer jobs which afford them the opportunity to apply their skills and abilities, offer them variety and freedom as well as jobs where they get constant feedback on how well they are doing. 88\% ( mean 4.6) of the respondents opined positively that if a job is highly motivating, employees are likely to be satisfied with the job content and deliver higher quality work, which in turn could lead to lower rates of absenteeism.

The result shows that $78 \%$ (mean 4.4) of the respondents agree that employee satisfaction is increased if the supervisor is emotionally supportive, allows for participation in decision-making and listens to employees' inputs.

Also, the result shows that $56 \%$ (mean 3.6) of the respondents accept to the new classical approach of management that if co-workers are friendly, competent and supportive, job satisfaction can be guaranteed. This is mainly because the work group normally serves as a source of support, comfort, advice and assistance to the individual worker. Hence, if an organization's veteran employees work hard and talk positively about their jobs; new employees will model this behaviour and be both productive and satisfied, this 
way absenteeism is reduced.

Working conditions refer to such aspects as temperature, lighting, noise and ventilation. 90\% (mean 4.2) of the respondents demonstrated that they prefer physical surroundings that are safe, clean, comfortable and with a minimum degree of distractions. With all these in place, job satisfaction is guaranteed and absenteeism placed on a barest minimum threshold.

One factor related to job satisfaction is the extent to which employees perceive that they are being treated fairly. Employees seek for policies and systems that they perceive to be fair as this will likely result in an increase in job satisfaction. Sequel to this, $72 \%$ (mean 4.1) of the respondents agree that fairness is a major key that drives absenteeism away in an organization.

This study further explores a link between job dissatisfaction and absenteeism. Result shows that $30 \%$ of the respondents strongly agree that absenteeism mean dissatisfaction while

$22 \%$ agree to this effect. This indicates that over half of the respondents agree that absenteeism means job dissatisfaction. Job dissatisfaction on the other hand results when the basic extrinsic sources of job satisfaction are missing in a particular organization. This is depicted in Table 2

Table 2: the perpetual view of Respondents showing link between absenteeism and job dissatisfaction?

\begin{tabular}{|l|c|}
\hline \multicolumn{1}{|c|}{ Parameters } & Percent \\
\hline Strongly disagree & 12.0 \\
\hline Disagree & 6.0 \\
\hline Undecided & 20.0 \\
\hline Agree & 22.0 \\
\hline Strongly agree & 40.0 \\
\hline Mean & 3.72 \\
\hline
\end{tabular}

Source: Compilation of Primary data

The table 2 exhibits the link between absenteeism and low job motivation. The mean is 3.72 which indicate the good degree of significance between two variables.

\section{Result of Regression Analysis on the Relationship between Absenteeism of Employee and Job Satisfaction/Motivation}

\begin{tabular}{|c|r|l|l|l|l|l|l|l|}
\hline $\mathrm{N}$ & $\mathrm{df}$ & $\begin{array}{l}\text { Correlation } \\
\text { Co-efficient }\end{array}$ & $\begin{array}{l}\text { Co-Efficient } \\
\text { Determine }(\mathrm{R})^{2}\end{array}$ & Sig.level & t-cal & t-tab & f- tab & Remark \\
\hline 200 & 48 & 0.784 & 0.615 & 0.05 & 8.750 & 6.567 & 4.04 & Sig. \\
\hline
\end{tabular}

Source: Computational result of data

Since t-Cal (8.750) is greater that t-tab (6.567) rejects $\mathrm{H}_{\mathrm{O}}$ and accepts $\mathrm{H}_{1}$. Thus, there is a significant relationship between absenteeism and job satisfaction. (When $\mathrm{t}-\mathrm{cal}<\mathrm{t}$ tab, reject $\mathrm{H}_{1}$ and accept $\mathrm{H}_{\mathrm{O}}$, When $\mathrm{t}$ cal > t-tab, accept $\mathrm{H}_{1}$ and reject $\mathrm{H}_{\mathrm{o}}$ ). The correlation between absenteeism and motivation is 0.784 and Co-efficient determines is 0.615 which is having high positive degree of relationship. It can be concluded that employee's job satisfaction depends upon motivation and the same is associated with absenteeism. Than where there is low job motivation absenteeism is more.

\section{Conclusion and limitation}

High level of absenteeism is caused by low job motivation. Employees' are getting different kinds of leave with pay and all types of amenities to take care of their obligation as and when it requires. Apart from this employees' are remaining absent from their work is other words known as absenteeism. Job dissatisfaction means low job motivation is the main cause that leads to absenteeism of an employee. There are two factors like intrinsic and extrinsic regulating job motivation of an employee. Extrinsic factors play a pivotal role in this matter because it links with, remuneration, promotional status, leadership quality, working conditions and behavioral approach of working group. In the absence of any one affects the psychological activities of an employee which leads to frustration and de-motivation to their job. Frustration and de-motivation to job inter alia encourages absenteeism. To find out the relationship between low motivation and absenteeism co-efficient correlation, t-tab, t-cal, f-tab statistical tools are used and the result shows that there is a significant positive relationship between absenteeism and low job motivation. It is the prime responsibility of the employer to pay due attention to motivate the employee so as to minimize absenteeism. The limitation of this study is that the 
findings cannot be accepted as cent percent correct as the scope, time and size of sample is very less. With this small size of sample of a single organization the result cannot be considered genuine. Hence further study is very essential in the matter.

\section{Reference}

[1]. Anderson, A.E. (2004). What's absent in absence management. Employee Benefits

[2]. George, J.M., \& Jones, G.R. (2002). Organisational behaviour. (3rd ed.). New Jersey: Prentice Hall.

[3]. Hardy, G.E., Woods, D \& Wall, T.D. (2003). The impact of psychological distress on absence from work. Journal of Applied Psychology 88 (2) : 306-314. Journal 29 (1) : 25-30

[4]. Johns, Gary (2007) "absenteeism" in George Ritzer (ed.) The Blackwell Encyclopedia of Sociology, Blackwell Publishing, 2007.

[5]. Luthans, F. (1995). Organizational behaviour. $\left(7^{\text {th }}\right.$ ed.). McGraw-Hill, Inc.

[6]. Mc Clenney, Mary Ann, "A Study of the Relationship between Absenteeism and Job Satisfaction, Certain Personal Characteristics, and Situational Factors for Employees in a Public Agency" (1992), Applied Research Projects, Paper 241

[7]. Rhodes, S.R., \& Steers, R.M. (1990). Managing employee absenteeism Addison: Wesley Publishing Company.

[8]. Robbins, S., Odendaal, A., \& Roodt, G. (2003). Organisational behaviour-Global and

[9]. Robbins, S.P. (1989). Organisational behaviour: Concepts, controversies and applications. (4th ed.). New Jersey : Prentice Hall. Southern African perspectives. South Africa: Pearson Education,

[10]. Spector, P.E. (1997). Job satisfaction: Application, assessment, causes and consequences. USA : SAGE Publications.

[11]. Steers, R., Porter, L., \& Bigley, G. (1996). Motivation and leadership at work (6 ${ }^{\text {th }}$ ed.). McGraw-Hill Companies, Inc. 